\title{
Blood Transfusion, Serum Ferritin, and Iron in Hemodialysis Patients in Africa
}

\author{
Leonard Kouegnigan Rerambiah, ${ }^{1}$ Laurence Essola Rerambiah, ${ }^{2}$ Armel Mbourou Etomba, ${ }^{3}$ \\ Rose Marlène Mouguiama, ${ }^{1}$ Phanie Brunelle Issanga, ${ }^{1}$ Axel Sydney Biyoghe, ${ }^{1}$ \\ Batchelili Batchilili, ${ }^{4}$ Sylvestre Akone Assembe, ${ }^{1}$ and Joel Fleury Djoba Siawaya ${ }^{1,5}$ \\ ${ }^{1}$ Centre National de Transfusion Sanguine (CNTS), Libreville, Gabon \\ ${ }^{2}$ Service d'Anesthésie-Réanimation du Centre Hospitalier Universitaire de Libreville, Libreville, Gabon \\ ${ }^{3}$ Centre National d'Hémodialyse de Libreville, Libreville, Gabon \\ ${ }^{4}$ Centre Hospitalier Universitaire d'Angondjè, Libreville, Gabon \\ ${ }^{5}$ Unité de Recherche et de Diagnostic Spécialisé/Laboratoire National de Santé Publique (URDS/LNSP), Libreville, Gabon
}

Correspondence should be addressed to Joel Fleury Djoba Siawaya; joelfleury@yahoo.com

Received 13 October 2014; Revised 8 December 2014; Accepted 11 December 2014

Academic Editor: Rajendra Chaudhary

Copyright (c) 2015 Leonard Kouegnigan Rerambiah et al. This is an open access article distributed under the Creative Commons Attribution License, which permits unrestricted use, distribution, and reproduction in any medium, provided the original work is properly cited.

\begin{abstract}
Background and Objectives. There is no data analyzing the outcome of blood transfusions and oral iron therapy in patients with kidneys failure in sub-Saharan Africa. The present study aimed to fill that gap and assess the value of ferritin in the diagnosis of iron overload and deficiency. Design. From January to February 2012, we prospectively studied 85 hemodialysis patients (78\% of males and $22 \%$ of females aged 20 to 79 years) attending the Gabonese National Hemodialysis Centre. Results. Correlation studies showed (a) a strong positive linear relationship between the number of blood transfusions and high serum ferritin in hemodialysis patient (Spearman $r$ : 0.74; $P$ value: 0.0001); (b) a weak association between the number of blood transfusions and serum iron concentrations (Spearman $r$ : 0.32; $P$ value: 0.04); (c) a weak association between serum ferritin and serum iron (Spearman $r$ : 0.32; $P$ value: 0.003$)$. Also, the strength of agreement beyond chance between the levels of ferritin and iron in the serum was poor $(\kappa=0.14)$. The prevalence of iron overload was $10.6 \%$, whereas the prevalence of iron deficiency was $2.3 \%$, comparing $(1)$ patients with a maximum of one transfusion not on iron therapy; (2) patients with a maximum of one transfusion on iron therapy; (3) polytransfused patients not on iron therapy; and (4) polytransfused patients on oral iron therapy. The "Kruskal-Wallis test" showed that ferritin levels varied significantly between the groups ( $P$ value: 0.0001$)$. Conclusion. Serum ferritin is not reliable as a marker of iron overload. For patients undergoing regular transfusion we recommend routine serum ferritin measurement and yearly measurement of LIC.
\end{abstract}

\section{Introduction}

Renal anemia due to iron-restricted erythropoiesis is common condition associated with chronic renal failure [1, 2]. Kidneys secrete erythropoietin, a protein involved in erythropoiesis. When kidneys are damaged, the secretion of erythropoietin decreases, resulting in renal anemia [3]. Because iron is also required for erythropoiesis, low iron may also cause anemia $[3,4]$. Blood transfusion, erythropoietin (EPO), and iron therapy remain the principal means to treat renal anemia in most settings [3-6]. However, renal anemia correction in chronic renal failure patients not only carries a risk for iron overload $[7,8]$, but also increases the risk of adverse events such as hypertension, congestive heart failure, myocardial infarction, and vascular access thrombosis $[3,9]$.

Correction of renal anemia in the Gabonese setting continues for the big part to be done by iterative blood transfusions and oral iron therapy. Although transfusions are considerably safer nowadays [10], transfusion-related risks persist [11-13]. These risks include transmission of infectious 
TABLE 1: Ferritin and iron ranges in the serum and interpretations.

\begin{tabular}{lcccc}
\hline & Iron deficiency & Normal & Indeterminate (moderately high) & Iron overload \\
\hline Serum ferritin & $<100 \mathrm{ng} / \mathrm{mL}$ & & $200-800 \mathrm{ng} / \mathrm{mL}$ & $>800 \mathrm{ng} / \mathrm{mL}$ \\
Serum iron & $<4 \mathrm{ng} / \mathrm{mL}$ & $5-15 \mathrm{ng} / \mathrm{mL}$ & & $>15 \mathrm{ng} / \mathrm{mL}$ \\
\hline
\end{tabular}

TABLE 2: Patients' distribution according to their ferritin and iron levels in the serum.

\begin{tabular}{|c|c|c|c|c|}
\hline & \multicolumn{4}{|c|}{ Serum ferritin } \\
\hline & $\begin{array}{l}\text { Iron deficiency } \\
(<100 \mathrm{ng} / \mathrm{mL})\end{array}$ & $\begin{array}{c}\text { Indeterminate } \\
(200-800 \mathrm{ng} / \mathrm{mL})\end{array}$ & $\begin{array}{l}\text { Iron overload } \\
(>800 \mathrm{ng} / \mathrm{mL})\end{array}$ & Total \\
\hline \multicolumn{5}{|l|}{ Serum iron } \\
\hline Iron deficiency $(<4 \mathrm{ng} / \mathrm{mL})$ & 2 & 4 & 3 & 9 \\
\hline Normal (5-15 ng/mL) & 12 & 22 & 24 & 58 \\
\hline Iron overload (>15 ng/mL) & 1 & 8 & 9 & 18 \\
\hline Total & 15 & 34 & 36 & 85 \\
\hline
\end{tabular}

agents $[11,14,15]$, the development of alloimmunization [16, 17], and iron overload [18]. Additionally, significant costs are associated with blood transfusions and EPO therapy to which few patients have access.

Currently there is no data in sub-Saharan Africa analyzing the outcome of blood transfusions and oral iron therapy in patients with kidneys failure. The present study aimed to evaluate iron status in patients with renal failure undergoing hemodialysis and assess the value of ferritin in the diagnosis of iron overload and iron deficiency in an African setting.

\section{Material and Methods}

From January to February 2012, in a prospective crosssectional study, we studied 85 hemodialysis patients $(78 \%$ males and $22 \%$ females aged 20 to 79 years) attending the Gabonese National Hemodialysis Centre. Patients were divided into four (4) groups. Group one (1) consists of patients with zero (0) or one (1) transfusion under no iron therapy; group two (2) consists of patients with zero (0) or one (1) on iron therapy; group three (3) consists of polytransfused patients under no iron therapy; group four (4) consists of polytransfused patients on oral iron therapy.

2.1. Sample Handling. Blood samples were taken before the hemodialysis session. $5 \mathrm{~mL}$ of venous blood was collected into plain tubes. The collected blood samples were then centrifuged (5000 rev/min for 10 minutes) and sera stored at $-80^{\circ} \mathrm{C}$ pending analysis.

2.2. Enzyme-Linked Fluorescence Assay. Commercially available ELFA kits were used to measure iron and ferritin in the serum (Biomérieux, France). Samples were assayed according to the manufacturer's protocol. Samples were read using a mini-VIDAS reader set to $450 \mathrm{~nm}$. The mini-VIDAS system software generated concentrations of the respective analytes.

2.3. Data Analysis. Table 1 shows ferritin and iron concentration ranges in the serum and the corresponding interpretations. The strength of agreement between serum concentrations of ferritin and iron was assessed based on the Kappa coefficient $(\kappa)$ that was calculated using the formula $\kappa=$ $\left(P_{o}-P_{e}\right) / 1-P_{e}$, where $P_{o}$ is the relative observed agreement among raters and $P_{e}$ is the hypothetical probability of chance agreement. All other statistical analyses were performed using Prism 6 software from GraphPad Software (San Diego, California, USA). The differences between the groups were analyzed using the Kruskal-Wallis multiple comparison test and Dunn's post test. A $P$ value below 5\% was considered significant.

2.4. Ethics. The National Laboratory of Public Health board and the National Blood Transfusion Centre board approved the study. All patients consented to participate in the study.

\section{Results}

3.1. Correlation between Transfusion, Ferritin, and Iron Levels. Data showed a positive and significant correlation between the number of transfusions and ferritin levels (Spearman $r$ : 0.74 ; $P$ value: 0.0001 ) (Figure $1(\mathrm{a})$ ). Although weak, the correlation between the number of transfusions and serum iron levels was positive and significant (Spearman $r: 0.32 ; P$ value: 0.04 ) (Figure 1(b)). Further correlation analysis showed a significant association between serum ferritin and serum iron concentrations (Spearman $r$ : $0.32 ; P$ value: 0.003 ) (Figure 1(c)). However, the observed Spearman $r$ coefficient suggested that although significant, the correlation between serum ferritin and serum iron concentrations is weak.

3.2. Strength of Agreement between Ferritin and Iron Levels in Establishing Iron Overload. Table 2 shows patients distribution according to their ferritin and iron levels in our setting. The prevalence of iron overload based on serum ferritin was $42.3 \%$. When assessed based on serum iron level iron overload prevalence was $21.2 \%$. The prevalence of iron overload based on both ferritin and iron concentration in the serum was $10.6 \%$. The prevalence of iron deficiency based on serum ferritin was $17.4 \%$, whereas the prevalence of iron deficiency based on serum iron concentration was $10.6 \%$. $2.3 \%$ was the prevalence of iron deficiency when both ferritin and iron concentration were crossed. 


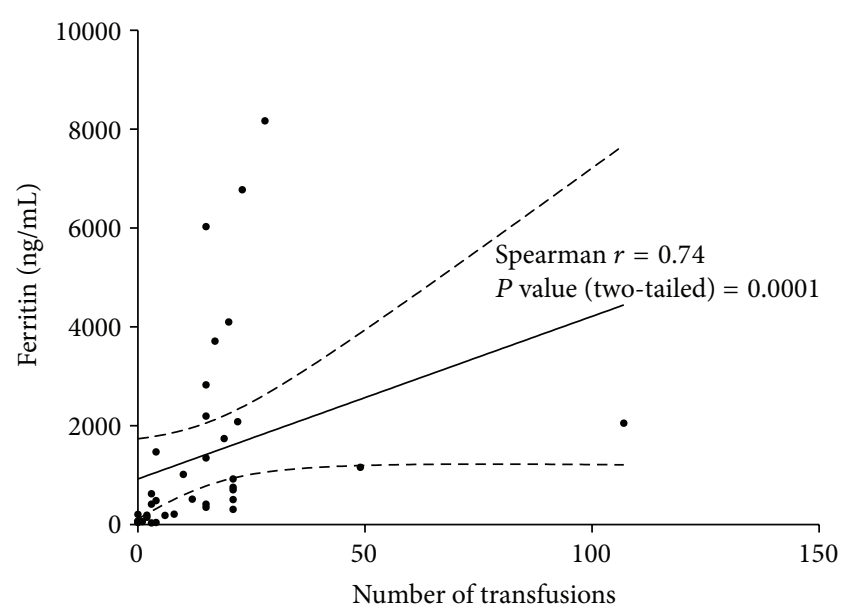

(a)

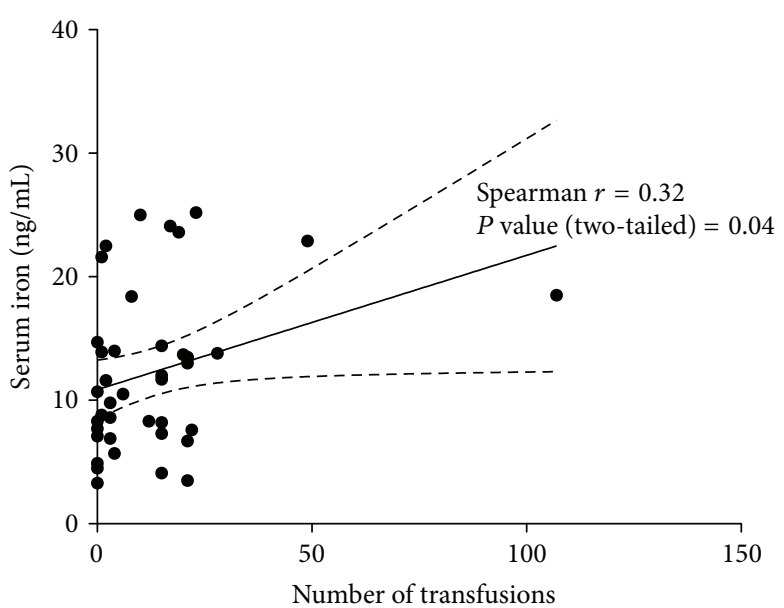

(b)

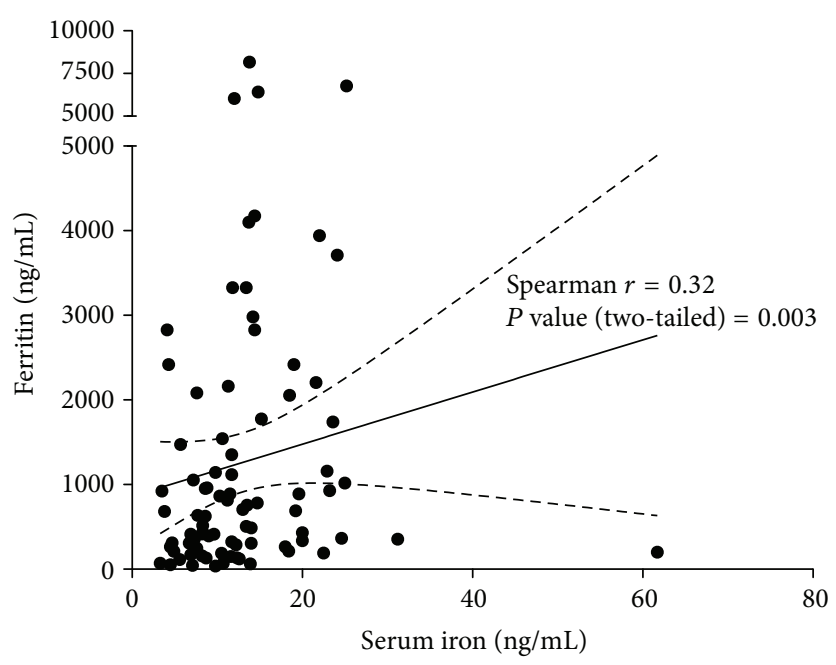

(c)

FIGURE 1: Correlation between (a) serum ferritin and the number of blood transfusions: the graph shows strong positive linear relationship between the number of blood transfusions and high serum ferritin in hemodialysis patient (Spearman $r: 0.74 ; P$ value: 0.0001 ); (b) serum iron and the number of blood transfusions: the graph shows a weak association between the number of blood transfusions and serum iron concentrations (Spearman $r: 0.32$; $P$ value: 0.04 ); (c) serum ferritin and serum iron: the graph shows a weak association between serum ferritin and serum iron (Spearman $r: 0.32 ; P$ value: 0.003 ).

Applying Cohen's Kappa $(\kappa)$ formula we got a $\kappa$ coefficient of 0.14 . Therefore strength of agreement beyond chance between the levels of ferritin and iron in the serum was weak or poor.

\subsection{Transfusion and Serum Ferritin and Iron. Comparing} patients with zero (0) or one (1) transfusion (on iron therapy and not on iron therapy) to polytransfused patients (on iron therapy and not on iron therapy), the "Kruskal-Wallis test" showed that ferritin levels varied significantly between the groups ( $P$ value: 0.0001$)$. "Dunn's Multiple Comparison Test" showed that (1) in patients not on iron therapy ferritin level was significantly higher in polytransfused patients than patients with zero $(0)$ or one (1) transfusion ( $P$ value: 0.0001$)$, (2) in patients on iron therapy ferritin level was significantly higher in polytransfused patients than patients who had zero $(0)$ or one (1) transfusion ( $P$ value $<0.05)$, (3) polytransfused patients on iron therapy had significantly higher levels of ferritin compared to patients who had zero (0) or one (1) transfusion who were not on iron therapy ( $P$ value: 0.001 ), and (4) polytransfused patients who were not on iron therapy had significantly higher levels of ferritin compared to patients who had zero (0) or one (1) transfusion and who were on iron therapy $(P$ value $<0.05)$ (Figure 2$)$. Comparing the same groups of patients for their serum iron concentrations, the "Kruskal-Wallis test" showed no significant differences between the groups.

\section{Discussion}

In the developing world the serum level of ferritin in patients is still used as the principal marker for diagnosis of iron overload or deficiency in hemodialysis patients. Monitoring iron status using serum ferritin may be subtle for hemodialysis 


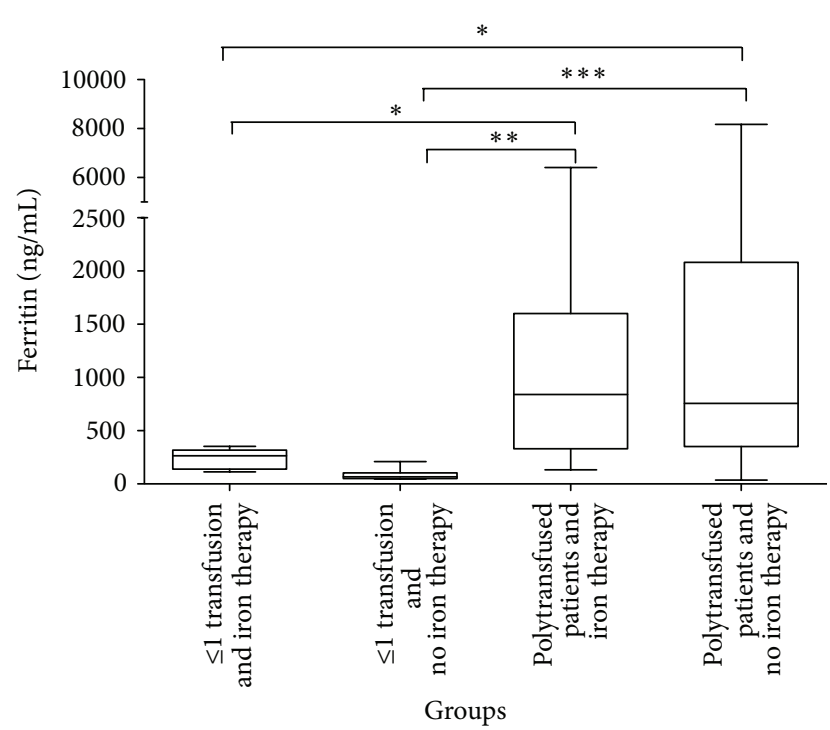

FIgURE 2: Serum ferritin levels in (1) patients with zero or one transfusion under no iron therapy; (2) patients with zero or one under iron therapy; (3) polytransfused patients under no iron therapy; (4) polytransfused patients under oral iron therapy. The star $(*)$ marks significant differences between groups. ${ }^{* * *} P$ value of $0.0001 ;{ }^{* *} P$ value of $0.001 ;{ }^{*} P$ value $<0.05$.

services workers, as there are confounding factors such as acute, chronic inflammation and malnutrition that could lead to differential when interpreting serum ferritin values [19]. Here we showed a strong positive linear relationship between the number of blood transfusions and high levels of serum ferritin. We also showed a weak association between the number of blood transfusions and the concentrations of iron in the serum. The strength of agreement between ferritin and iron levels in the serum was poor. Data suggests that multiple transfusions increase substantially serum ferritin and to a lesser extent serum iron.

We found that in hemodialysis patients serum ferritin greatly overestimates iron burden. Serum ferritin overestimates also iron deficiency, but to a lesser extent. Indeed, in our setting, the prevalence of iron overload based on serum ferritin was 42.3 whereas the prevalence of iron overload based on serum iron levels was $21.2 \%$. The prevalence of iron deficiency based on serum ferritin and serum iron was, respectively, $17.4 \%$ and $10.6 \%$. Data also showed that $65 \%$ of patient who had moderately high serum ferritin levels and $67 \%$ of patients who had very high serum ferritin levels had their serum iron level within the normal range. Therefore, our results denote and confirmed that high serum ferritin is not a reliable marker of iron overload [20,21].

Because the use of serum ferritin as marker for iron overload or deficiency could lead to (1) withholding iron therapy in patients that need it and (2) giving iron treatment to patients who do not require it, accurate assessment of the body iron load is essential to prevent iron toxicity and to manage iron chelation therapy. Although we did not assess liver iron concentration (LIC) by magnetic resonance imaging (MRI), based on the published report [3, 22-25], we could recommend it for the management of hemodialysis patients in developing countries. However, MRI-based methods are still relatively expensive in that part of the world. Therefore the accurate diagnosis and management of iron overload in developing countries remain challenging. In these countries, for patients undergoing regular transfusion therapy we would suggest to associate with the routine serum ferritin measurement, a yearly measurement of LIC as proposed by Hoffbrand and colleagues [22].

\section{Conflict of Interests}

The authors declare that there is no conflict of interests.

\section{Authors' Contribution}

Leonard Kouegnigan Rerambiah has conducted study design, samples collection, samples and data analysis supervision, and paper preparation; Laurence Essola Rerambiah, Armel Mbourou Etomba, Rose Marlène Mouguiama, Phanie Brunelle Issanga, Batchelili Batchilili, and Sylvestre Akone Assembe have conducted samples and data collection; Joel Fleury Djoba Siawaya has conducted study design, supervision, data analysis, and paper preparation.

\section{Acknowledgments}

The authors acknowledge the Gabonese National Hemodialysis Center for its participation in this study by giving them access to its patients. They also acknowledge the Gabonese National Blood Transfusion Center for logistics and financial supports.

\section{References}

[1] E. Urrechaga, L. Borque, and J. F. Escanero, "Erythrocyte and reticulocyte indices in the assessment of erythropoiesis activity and iron availability," International Journal of Laboratory Hematology, vol. 35, no. 2, pp. 144-149, 2013.

[2] L. T. Goodnough, E. Nemeth, and T. Ganz, "Detection, evaluation, and management of iron-restricted erythropoiesis," Blood, vol. 116, no. 23, pp. 4754-4761, 2010.

[3] C. E. Lankhorst and J. B. Wish, "Anemia in renal disease: diagnosis and management," Blood Reviews, vol. 24, no. 1, pp. 39-47, 2010.

[4] V. Ramanath, D. Gupta, J. Jain, K. Chaudhary, and R. Nistala, "Anemia and chronic kidney disease: making sense of the recent trials," Reviews on Recent Clinical Trials, vol. 7, no. 3, pp. 187-196, 2012.

[5] T. Kapoian, "Challenge of effectively using erythropoiesis-stimulating agents and intravenous iron," The American Journal of Kidney Diseases, vol. 52, pp. S21-S28, 2008.

[6] W. H. Hörl, Y. Vanrenterghem, B. Canaud et al., "Optimal treatment of renal anaemia (OPTA): improving the efficacy and efficiency of renal anaemia therapy in haemodialysis patients receiving intravenous epoetin," Nephrology Dialysis Transplantation, vol. 20, supplement 3, pp. iii25-iii32, 2005.

[7] P. Van Buren, R. L. Velez, N. D. Vaziri, and X. J. Zhou, "Iron overdose: a contributor to adverse outcomes in randomized 
trials of anemia correction in CKD," International Urology and Nephrology, vol. 44, no. 2, pp. 499-507, 2012.

[8] H. Ghoti, E. A. Rachmilewitz, R. Simon-Lopez et al., "Evidence for tissue iron overload in long-term hemodialysis patients and the impact of withdrawing parenteral iron," European Journal of Haematology, vol. 89, no. 1, pp. 87-93, 2012.

[9] K. S. Gill, P. Muntner, R. A. Lafayette et al., "Red blood cell transfusion use in patients with chronic kidney disease," Nephrology Dialysis Transplantation, vol. 28, no. 6, pp. 1504-1515, 2013.

[10] W. H. Dzik, H. Corwin, L. T. Goodnough et al., "Patient safety and blood transfusion: new solutions," Transfusion Medicine Reviews, vol. 17, no. 3, pp. 169-180, 2003.

[11] L. T. Goodnough, "Risks of blood transfusion," Critical Care Medicine, vol. 31, no. 12, pp. S678-S686, 2003.

[12] L. T. Goodnough, A. Shander, and M. E. Brecher, "Transfusion medicine: looking to the future," The Lancet, vol. 361, no. 9352, pp. 161-169, 2003.

[13] Y. C. Tanhehco and J. S. Berns, "Red blood cell transfusion risks in patients with end-stage renal disease," Seminars in Dialysis, vol. 25, no. 5, pp. 539-544, 2012.

[14] L. K. Rerambiah, L. E. Rerambiah, C. Bengone, and J. F. Djoba Siawaya, "The risk of transfusion-transmitted viral infections at the Gabonese National Blood Transfusion Centre," Blood Transfusion, vol. 12, no. 3, pp. 330-333, 2014.

[15] C. T. Tagny, E. L. Murphy, and J.-J. Lefrère, “The Francophone Africa blood transfusion research network: a five-year report (2007-2012)," Transfusion Medicine, vol. 23, no. 6, pp. 442-444, 2013.

[16] M. Baby, S. Fongoro, M. Cissé et al., "Frequency of red blood cell alloimmunization in polytransfused patients at the university teaching hospital of Point G, Bamako, Mali," Transfusion Clinique et Biologique, vol. 17, no. 4, pp. 218-222, 2010.

[17] J. S. Shukla and R. K. Chaudhary, "Red cell alloimmunization in multi-transfused chronic renal failure patients undergoing hemodialysis," Indian Journal of Pathology and Microbiology, vol. 42, no. 3, pp. 299-302, 1999.

[18] R. M. Hakim, J. C. Stivelman, G. Schulman et al., "Iron overload and mobilization in long-term hemodialysis patients," American Journal of Kidney Diseases, vol. 10, no. 4, pp. 293-299, 1987.

[19] J. B. Wish, "Assessing iron status: beyond serum ferritin and transferrin saturation," Clinical Journal of the American Society of Nephrology, vol. 1, supplement 1, pp. S4-S8, 2006.

[20] K. Kalantar-Zadeh and G. H. Lee, "The fascinating but deceptive ferritin: to measure it or not to measure it in chronic kidney disease?" Clinical Journal of the American Society of Nephrology, vol. 1, supplement 1, pp. S9-S18, 2006.

[21] K. Kalantar-Zadeh, F. C. Luft, M. H. Humphreys, J. W. Eschbach, and J. W. Adamson, "Moderately high serum ferritin concentration is not a sign of iron overload in dialysis patients," Kidney International, vol. 56, no. 2, pp. 758-759, 1999.

[22] A. V. Hoffbrand, A. Taher, and M. D. Cappellini, "How I treat transfusional iron overload," Blood, vol. 120, no. 18, pp. 36573669, 2012.

[23] T. G. St. Pierre, P. R. Clark, and W. Chua-Anusorn, "Measurement and mapping of liver iron concentrations using magnetic resonance imaging," Annals of the New York Academy of Sciences, vol. 1054, pp. 379-385, 2005.

[24] T. G. St. Pierre, P. R. Clark, W. Chua-Anusorn et al., "Noninvasive measurement and imaging of liver iron concentrations using proton magnetic resonance," Blood, vol. 105, no. 2, pp. 855-861, 2005.
[25] T. G. St. Pierre, A. El-Beshlawy, M. Elalfy et al., "Multicenter validation of spin-density projection-assisted R2-MRI for the noninvasive measurement of liver iron concentration," Magnetic Resonance in Medicine, vol. 71, no. 6, pp. 2215-2223, 2014. 


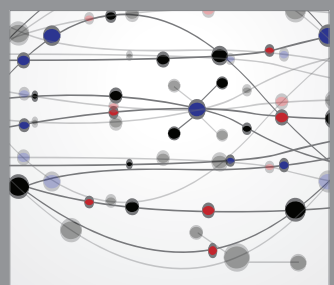

The Scientific World Journal
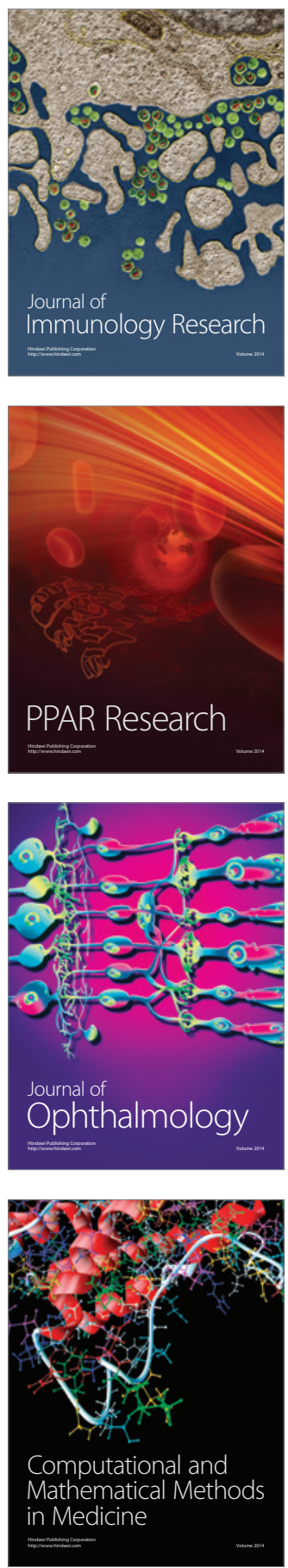

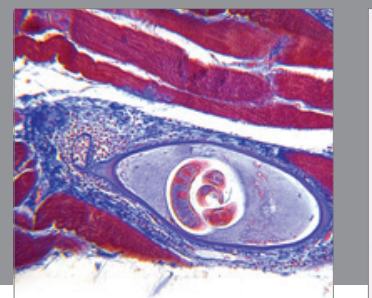

Gastroenterology

Research and Practice
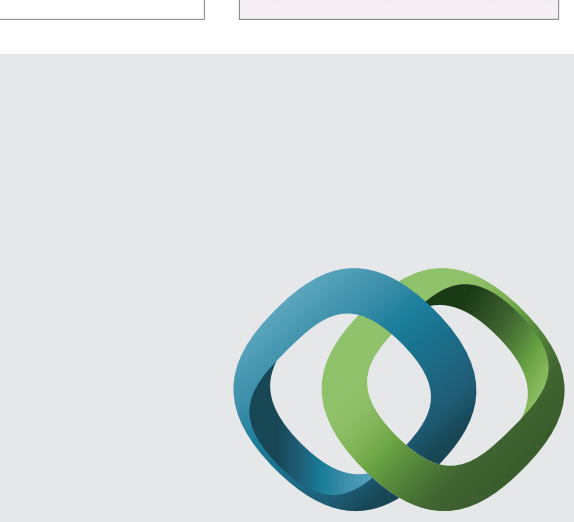

\section{Hindawi}

Submit your manuscripts at

http://www.hindawi.com
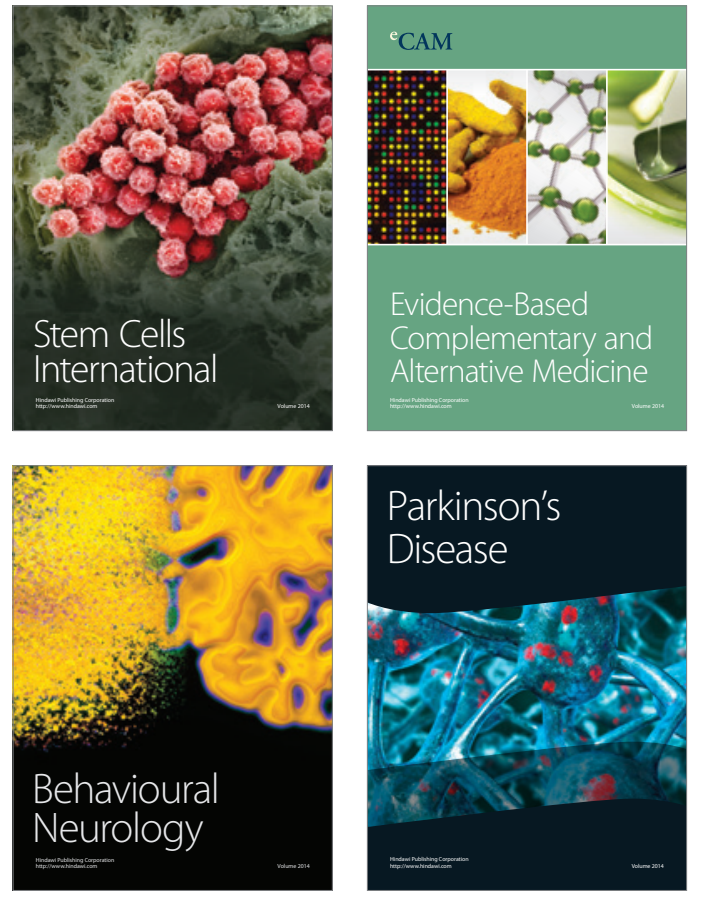
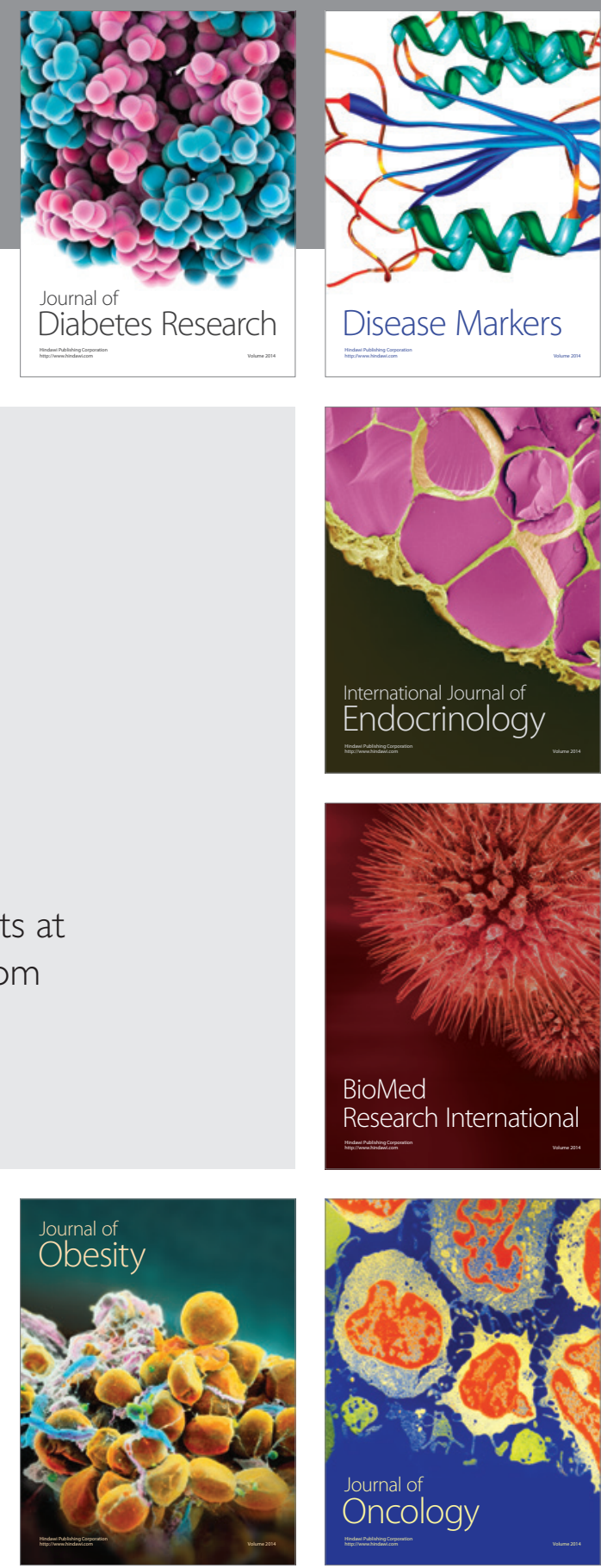

Disease Markers
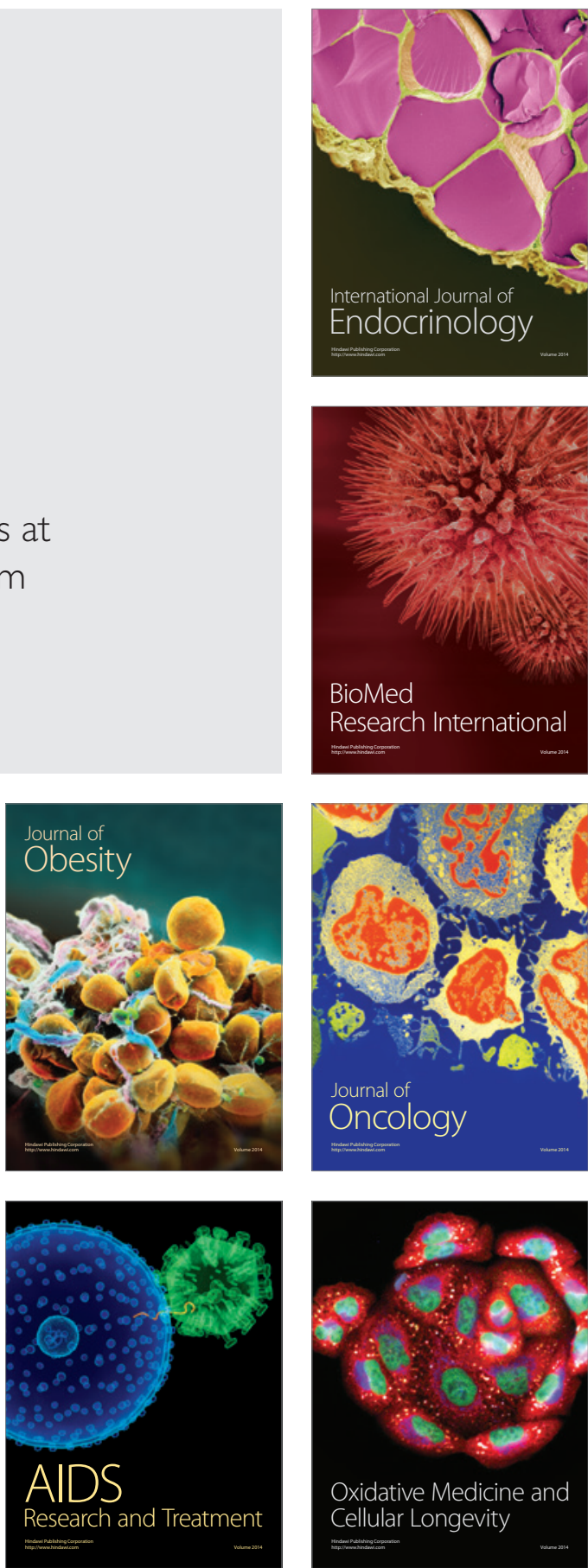